\title{
LITERATURA NEGRA, CULTURA E FORMAÇÃO CIDADÃ ANTIRRACISTA
}

\author{
BLACK LITERATURE, CULTURE AND ANTI-RACIST CITIZEN FORMATION
}

\author{
César Costa Vitorino ${ }^{1}$ \\ Edna Maria de Oliveira Ferreira ${ }^{2}$
}

Recebido: 14/04/2021

Aceito: 08/06/2021

Resumo: Este artigo propõe a leitura de textos da literatura negra, em contexto escolar de Ensino Médio, como instrumento de reflexão em prol da formação cidadã antirracista, resultando em movimentos de aproximação à história, às crenças, saberes e cultura africana e afrodescendentes. Objetivou-se compreender como a literatura e a cultura negra transitam nesse contexto, sendo vetores de valorização das raízes culturais e da construção das identidades negras, visando a mobilizar ações e atitudes antirracistas. Parte-se da análise do corpus, composto por respostas dadas a um questionário online, dirigido a sujeitos professores e alunos desse segmento de ensino para compreender como a história, as tradições e a cultura afrodescendentes fazem parte do currículo escolar, conforme se ajustem a cada conteúdo dos diversos componentes curriculares, como forma de garantir a presença desses conhecimentos na formação cidadã dos sujeitos alunos, independentemente da cor, raça ou crença. O uso da literatura e cultura negra pode ser uma maneira de incrementar as ações advindas a partir da instituição da Lei 10. 639/03, ampliada pela Lei 11. 649/08, que não tem se mostrado suficiente no combate ao racismo estrutural. Percebeu-se a necessidade de mais espaço para ações que se desenvolvam dentro da escola e resultem num trabalho não só de conscientização, mas ainda em movimentos, atitudes e ações antirracistas também fora da escola. Os estudos de Almeida (2019); Ribeiro (2019), Borges (2019); Santos (1998), dentre outros, respaldarão a argumentação.

Palavras-chave: Racismo; antirracismo; literatura negra; contexto escolar de Ensino Médio.

Abstract: This article proposes the reading of texts from black literature in a high school context, as an instrument $\mathrm{f}$ reflection in favor anti-racist citizen formation, resulting in movements of approximation to African and Afro-descendant history, beliefs, knowledge and culture. The objective was to understand how literature and black culture move in this context, being vectors for cultural value roots and the construction of black identities, aiming to mobilize anti-racist actions and attitudes. It starts from the analysis of the corpus, composed of answers

\footnotetext{
${ }^{1}$ Doutor em Letras (PUCRS), professor adjunto na área de linguagens da UNEB, campus I, Salvador-BA e orientador de tese da autora.

${ }^{2}$ Mestre em Educação Agrícola (UFRRJ), professora EBTT de Língua Portuguesa, no Instituto Federal de Educação, Ciência e Tecnologia Baiano, campus Senhor do Bonfim (IF Baiano), cursa estudos de doutorado em Educação na Universidade Nacional de Rosário-Argentina (UNR).
} 
given to an online questionnaire, addressed to subjects teachers and students of this teaching segment to understand how the Afro-descendant history, traditions and culture are part $\mathrm{f}$ the school, curriculum, as they adjust to each content of the various curricular components, as a way to guarantee the presence of this knowledge in the citizen formation of the student subjects, regardless of color, race or belief. It may be a way to increase the actions arising from the institution of Law 10.639/03, expanded by Law 11.649/08, which has not proved to be sufficient in the fight against structural racism. The need for more space for actions developed within the school and resulting not only in awareness-raising work, but also in movements, attitudes and anti-racist actions outside the school. Almeida's studies (2019), Ribeiro (2019), Borges 92019), Santos (1998), among others, will support the argument.

Keywords: Racism; anti-racism; black literature; high school context.

\section{Introdução}

Na palestra proferida por Teun A. van Dijk no Projeto Abralin ao vivo: Linguistcs online, dia 09/11/2020, o termo racismo é definido como um sistema de abuso de poder e violência, imposto pelo poder hegemônico branco (ou elite simbólica) que controla e reproduz o discurso público racista e que, em seguida, é disseminado e aprendido por toda a sociedade de forma estruturante. O palestrante acrescenta ainda que, assim como o racismo é aprendido, o antirracismo também poderá sê-lo.

Dessa forma, propõe em seu livro 'O discurso antirracista no Brasil', a ser lançado em breve também em língua portuguesa, uma teoria do antirracismo compreendida como movimento de resistência e militância. E argumenta que o indivíduo que participa de ações e movimentos antirracistas desenvolve modelos mentais pessoais e cria representações desses eventos a partir de suas emoções, atitudes, vivências, opiniões e conhecimentos (cognição social) sobre o antirracismo. Daí a necessidade de se motivar atitudes e eventos dessa natureza, na escola, na família e em toda a sociedade com perspectivas críticas e positivas de aceitação do outro, do diferente.

Sabe-se que, além da conscientização e da solidarização de todos sobre os problemas vividos cotidianamente pelos negros (ou pelo diferente) em nosso meio, há que mobilizar a sociedade para o combate ao racismo, a partir de movimentos e ações profícuas e bem estruturadas, tomando por base a subjetividade do negro (do diferente), e não somente a dos brancos, para que não se incorra no esvaziamento da luta, como tem acontecido com as lutas pelos direitos cidadãos ou o direito das mulheres, em que apenas os brancos (ou as mulheres brancas) se sentem contemplados. Ou seja, a falsa ideia de democracia racial (todos são iguais 
perante a lei) vigente na sociedade, impede que os direitos e anseios das mulheres negras também sejam listados nessas lutas (RIBEIRO, 2019).

Mesmo depois de um século da abolição da escravidão, que durou 300 anos no Brasil, os negros veem-se marginalizados e encontram dificuldades em se constituir plenamente como cidadãos. Haja vista os hábitos, comportamentos, ações e falas preconceituosas e segregadoras banalizadas diariamente na sociedade, acentuando cada vez mais os distanciamentos e evidenciando o racismo estrutural presente entre todos (ALMEIDA, 2016). Logo, perceber o racismo entranhado nas mentes e almas é um dos primeiros passos a ser alcançado por aquele que se dispõe a conhecer e combater o racismo.

Mas isso parece estar longe de acontecer. Recentemente, o Brasil assistiu às falas do presidente e do vice-presidente em entrevistas concedidas à imprensa, nas quais negam a possibilidade de existir racismo no Brasil. Para ambos é apenas um modismo copiado dos movimentos negros que acontecem nos EUA, a exemplo do Black lives matter, com interesse em causar balbúrdia na sociedade brasileira e beneficiar partidos políticos de esquerda. Há outras formas de analisar essa mesma questão. Vejamos o que diz Boaventura Souza Santos.

Boaventura Souza Santos (2010) criou a metáfora "Epistemologias do Sul” para referirse a questões sobre colonialismo e decolonialismo, compreendendo colonialismo como dominação epistemológica que, aos poucos, precisa ceder espaço para diálogos mais horizontais entre a diversidade de conhecimentos existentes, numa ação de descolonização de saberes. Para esse autor (Id., p. 7),

o colonialismo, para além de todas as dominações por que é conhecido, foi também uma dominação epistemológica, uma relação extremamente desigual de saber-poder que conduziu à supressão de muitas formas de saber próprias dos povos e nações colonizadas, relegando muitos outros saberes para um espaço de subalternidade.

Boaventura, então, admite que durante os processos de colonização houve a supressão de conhecimentos locais; a tentativa de homogeneização do mundo, através da imposição da cultura e da história dominante, o que ele chama de "epistemicídio". Assim, a subalternidade do negro, o não respeito aos direitos humanos, as várias formas de preconceitos e racismos foram se disseminando e ficando cada vez mais evidentes nas sociedades, necessitando que os agentes e sujeitos sociais modernos e contemporâneos "reinventem os lugares", ou seja, busquem descolonizar os saberes impostos como superiores, criando espaço de debate mais amplos e mais democráticos como forma de combate a essas mazelas. Negar a existência está 
longe de ser solução para o problema, aliás é uma ação dispensável pelo seu alto grau de nocividade.

Os movimentos negros em contextos atuais, na verdade, são iniciativas que têm o intuito de caminhar nessa linha, coibir o racismo, a discriminação, o preconceito e a animalização do diferente. Há que se desenvolver ações que tragam essas questões sobre racismo para o centro das discussões. As pessoas precisam conhecer e entender o que é racismo; como ele se estrutura na sociedade; aprender a reconhecer as diferenças, atribuindo-lhes o valor devido, ao invés de tentar invisibilizá-las (RIBEIRO, 2019).

O conhecimento das raízes históricas, da cultura e de toda riqueza advinda da África deve ser visto como potencialidade e deve ser acampado pela sociedade brasileira como forma de criar situações de reflexão para que os privilégios dos brancos e o racismo internalizado por eles, e demonstrado até mesmo na linguagem opressora, possam ser repensados, como forma de devolver aos negros e às minorias seus direitos civis e subjetivos que lhes foram subtraídos. Afinal, concorda-se com Foucault (1999) quando defende o direito do outro de ser reconhecido em sua diversidade.

Desse modo, a sociedade, ao invés de tentar neutralizar as diferenças ou torná-las invisíveis, como costumeiramente acontece, poderá passar a compreendê-las em seus valores, o que poderá favorecer para que se evite perpetuar o mito da democracia racial que, segundo Ribeiro (op. cit., p. 9) "Essa visão paralisa a prática antirracista, pois romantiza as violências sofridas pela população negra ao escamotear a hierarquia racial com uma falsa ideia de harmonia". Ou seja, esse é mais um dos mitos que impede movimentos e ações antirracistas na sociedade.

Assim, faz-se necessário que a escola contribua para o fortalecimento da identidade negra ao mesmo tempo em que questione o lugar do branco na luta antirracista. E informar-se sobre o racismo e sobre a história da África, suas culturas, suas crenças, costumes, etc., é um passo importante para o combate ao racismo.

Diante desse quadro, e com o intuito de contribuir provocando reflexões sobre essa temática, foi realizada uma pesquisa online, com questionários semiestruturados disponibilizados a professores e alunos de ensino médio, em que puderam se posicionar sobre a questão da importância da representatividade negra na literatura e em outros conteúdos/atividades escolares, como ação significativa na desconstrução de atitudes racistas e preconceituosas que persistem na sociedade e no espaço escolar. Durante 30 dias, o questionário 
ficou disponível e um e-mail foi enviado à Coordenação de várias escolas de Ensino Médio, públicas e privadas, solicitando a colaboração, no sentido de divulgarem a pesquisa entre alunos e professores. No item 4 deste artigo serão feitas algumas considerações de discussões a partir dos dados coletados.

\section{Retomando dados históricos}

Os movimentos pelos direitos civis dos negros nas décadas de 50 e 60 do século passado, nos EUA, resultaram em conquistas, a exemplo de alguns programas que se propunham a oferecer igualdade de oportunidades, facilitando o acesso do negro a alguns espaços públicos, à universidade $\mathrm{e}$, consequentemente, inserindo-os no mundo do trabalho; e algumas políticas afirmativas de combate ao racismo. Martin Luther King Júnior, ativista pacífico, é a principal referência quando se fala em fim da segregação racial nos EUA (ANDREWS, 1985).

Esses movimentos nos EUA migraram para outros espaços como Europa e, inclusive para o Brasil, com conquistas também significativas, em que resultaram na formação de comissões, apoiadas e consentidas por alguns partidos políticos brasileiros para a criação de políticas públicas voltadas para as necessidades e para o atendimento dos direitos civis dos negros. Não se deve esquecer que o programa de Cotas Raciais, tanto nos EUA, em 1960, como no Brasil, em meados dos anos 2000, foi um ganho a partir desse contexto.

Com o acesso de pessoas negras nas universidades brasileiras também foi possível perceber a ausência de referências negras nas áreas da cultura, literatura, produções acadêmicas. Logo, se percebeu também o processo de "embranquecimento" sofrido por alguns dos autores para que pudessem ser aceitos pela imprensa editorial da época. Machado de Assis, embora ainda hoje muitos brasileiros se mostrem perplexos ao descobrirem sua origem negra, é um exemplo de escritor que sofreu esse processo de apagamento da cor da pele e de sua origem.

Em relação às dificuldades de acesso à imprensa editorial sofrida pelos autores de modo geral e pelos negros, de modo específico, Nogueira e Nogueira (2009, p.32), ao analisarem o pensamento bourdiano sobre conceitos estéticos que perduram no campo literário, afirmam que:

[...] é possível analisar como editores, escritores, críticos e pesquisadores das áreas de língua e literatura disputam espaço e reconhecimento para si mesmos e suas produções. Basicamente, o que está em jogo nesse campo são as definições sobre o que é boa e má literatura; quais são as produções artísticas ou de vanguarda e quais são os grandes escritores e quais são os escritores menores. 
A citação acima expõe os valores estéticos que permeavam a questão do espaço e do reconhecimento na imprensa editorial naquele contexto. Ou seja, os espaços eram bastante disputados, o que certamente, impunha dificuldades de acesso a qualquer autor. Portanto, aos escritores negros ou de temática negra nenhum ou quase nenhum espaço era reservado. E quando encontravam esse espaço sofria o processo de "embranquecimento", conforme mencionado anteriormente.

Muitos autores, a exemplo de Cruz e Souza, morreram à míngua, tendo que reconhecer (ou pelo menos sem poder questionar!) a suposta inferioridade de suas obras literárias, diante da falta de espaço na imprensa editorial para publicá-las; enquanto outros cederam, conscientes ou não, ao que Bourdieu chama de violência simbólica: a imposição de um padrão cultural (arbitrário cultural) como modelo único, sujeitando-se ao apagamento da cor da pele.

Entretanto, aos poucos percebeu-se também na literatura e na imprensa brasileira a divulgação de narrativas e de composição de personagens negras, periféricas e caricatas, produzidas em narrativas de temática negra, mas sob a subjetividade do branco e da égide colonialista. Isso vai fomentar ainda mais as discussões e movimentos em prol do combate ao racismo e da reparação dos direitos civis e subjetivos dos negros. Cria-se, assim, e graças à imposição de uma cultura e literatura branca, o clima propício para o surgimento da literatura negra no Brasil.

$\mathrm{O}$ conceito de literatura negra se fortaleceu em meados do século XX com o encorajamento desses movimentos negros, nos Estados Unidos e, em seguida no Brasil, servindo de instrumento de denúncias da segregação social infligida aos negros, bem como para direcionar os embates com vistas aos direitos civis do povo negro. Entende-se literatura negra como um campo/área dentro da literatura ${ }^{3}$ em que o sujeito de escrita, "o eu-enunciador", é o próprio negro que cria suas narrativas, suas personagens, seus pontos de vista, a partir de suas vivências, sentimentos ou subjetividades, com o intuito de demonstrar seus posicionamentos políticos e ideológicos (BERND, 1988), de modo a criar tensão, inclusive, com alguns conceitos e valores simbólicos hegemônicos vigentes na sociedade.

O discurso da literatura negra, desse modo, é o discurso da afirmação, o discurso que busca a desconstrução e reconstrução de identidades no sistema de significações ao qual se está imerso, colocando como ponto axial a aproximação da noção de identidade nacional

\footnotetext{
${ }^{3}$ Literatura tomada em seu conceito basilar expresso na plurissignificação, subjetividade, seleção das palavras e
} valor estético. 
homogênea e uniforme (CUTI, 2010). Temos aí o critério discursivo como elemento decisivo para conceituar a escrita negra; a escrita em que o emissor assume a condição e o discurso do negro e traz suas origens, suas ancestralidades, reinventando a representação, preconceituosa e estereotipada da imagem do negro ao longo dos séculos.

É válido observar que dentro do conceito de literatura negra cabem tendências literárias distintas, a depender do contexto em que ela surge, pois há peculiaridades próprias em ser negro neste ou naquele contexto espaço-temporal. Assim, pode-se falar em Negrismo Crioulo (Cuba), Negritude (Paris) ou produção negro-brasileira, etc. O importante é que essas tendências todas favoreceram uma afirmação/identidade negra, criando também uma consciência negra.

Todo esse contexto favoreceu para que em 2003 fosse criada, no Brasil, a Lei 10.639 que faz alterações na Lei de Diretrizes e Bases (Lei 9394/96), ao incluir no currículo oficial da rede de ensino a presença obrigatória dos estudos sobre História e Cultura Afro-brasileira e Africana. Em 2008, essa lei é ampliada pela Lei 11.645 que em seu Art. 26 estabelece a obrigatoriedade também dos estudos da cultura indígena, para os segmentos de ensino fundamental e médio. Mas como, de fato, essas leis acontecem dentro do espaço escolar de ensino médio? E qual espaço é dado às produções da literatura negra na escola e na sociedade? A literatura negra adentra os espaços escolares? Como professores e alunos avaliam a presença da cultura e d literatura negra nas escolas de ensino médio? Este artigo resulta de uma pesquisa que buscou, justamente, traçar esse panorama através dos dados de recolha.

Assim, mesmo que marginalizadas ainda pela grande imprensa editorial, as produções literárias sob a sensibilidade e ótica do negro continuam a existir, mesmo que invisibilizadas. Algumas dessas obras conseguiram ser publicadas sob o esforço de projetos especiais nascidos para esse propósito. Desse modo, temos excelentes narrativas advindas desse período ou criadas a partir de relatos em diários pessoais, como é o caso da obra Quarto de Despejo: diário de uma favelada, de Maria Carolina de Jesus, dentre tantas outras narrativas ou versos.

Toma-se aqui um que traz a temática da construção e valorização da identidade negra, ao mostrar que a imposição dos valores advindos da cultura eurocêntrica e colonialista (arbitrário cultural) pode fazer com que algumas pessoas que se autodeclaram pretas, cedam aos valores estéticos impostos pela cultura hegemônica e façam adesão ao apagamento dos traços fenotípicos e característicos de sua raça, em nome de uma estética ditada pela mídia e pelos discursos racistas e ideológicos como modelo ideal de beleza, apenas como exemplificação do que se entende por "eu-enunciador negro". 
Há no mesmo poema a exaltação ao fato de que mudam-se as características externas, fenotípicas, mas mantêm-se intactas as raízes, a consciência e o íntimo de cada uma dessas pessoas negras. Ou seja, há um contraponto à ideia anterior materializada no texto de tentativa de apagamento. E nisso, então, reside o orgulho de ser negro e a força para a resistência. Esse é o momento mais alto do poema como veiculador de ideias que fortalecem a teoria antirracista e o poder da literatura negra de promover a reflexão e dispersar conhecimento sobre a história e a cultura negra ou afrodescendente. Vejamos o poema Trincheira, de Luís Silva, também conhecido por Cuti.

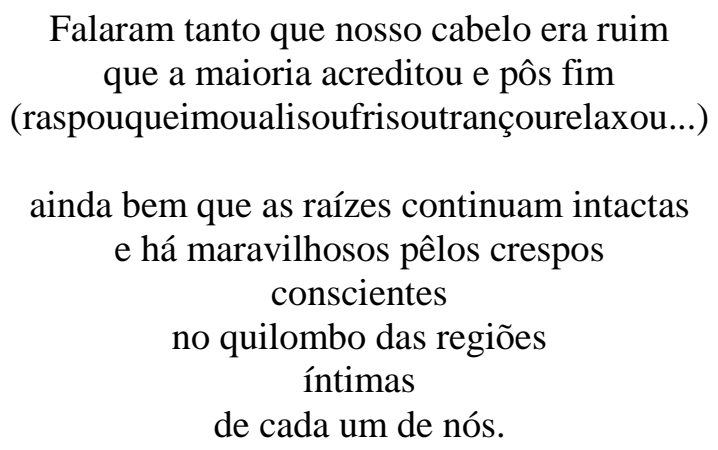

Fonte: Antologia de Poesia Afro-brasileira: 150 anos de consciência negra no Brasil.

Desse modo, defende-se neste artigo a viabilidade da inserção da verdadeira história da escravidão negra e da literatura e da cultura afrodescendentes nas escolas de ensino médio, uma vez que, embora com a instituição das leis acima descritas, a realidade já tenha sofrido alguns avanços até significativos, em relação à solidarização e à conscientização de muitos sobre as demandas dos negros na sociedade brasileira, faltam ainda muitas ações e movimentos antirracistas dentro dos contextos escolares e na sociedade brasileira como um todo.

E a escola tem muito a contribuir ao disseminar a história do negro e promover o debate acerca das raízes culturais afrodescendentes, sob uma visão crítica e sob a subjetividade negra, como forma de criar essa representatividade na formação de cada aluno. Um debate, partindo da poesia ou da prosa literária, sobre essas questões pode promover o engajamento solidário dos alunos que se autodeclaram brancos, despojando-os para a aceitação e identificação com a diversidade cultural. Pode colaborar para o alargamento de horizontes e a ruptura com preconceitos e valores pré-estabelecidos, no sentido de promoverem ações e atitudes anticolonialistas e antirracistas. Afinal, como diz Maldonado-Torres (2007, p. 131),

[...] apesar de o colonialismo preceder a colonialidade, a colonialidade sobrevive ao colonialismo. Ela se mantém viva em textos didáticos, nos critérios para o bom trabalho acadêmico, na cultura, no sentido comum, na 
autoimagem dos povos, nas aspirações dos sujeitos e em muitos outros aspectos de nossa experiência moderna.

Pode-se notar que não é um caminho fácil e certo; é um processo e, como todo processo, poderá ser lento e dispendioso. Entretanto, faz-se necessário combater algumas imposições colonialistas.

Logo, uma abordagem crítica da história, cultura e literatura negra em espaços escolares deve oportunizar efetivamente a convivência de várias culturas e minorias em um espaço comum. O que não pode nem deve acontecer mais, ao se trabalhar história, cultura e literatura negra é uma mediação didática limitada em sala de aula, com predomínio de uma visão romantizada que serve à ideologia da colonialidade, em que o negro/preto ou as minorias sejam estereotipados, subalternizados, o que é bastante comum quando essas questões são analisadas sob o ponto de vista da subjetividade do branco.

Precisa-se escancarar a história das origens negras em nosso território como, de fato, ela ocorreu. A esse respeito, Borges (2019, p. 39) assim se pronuncia:

a primeira mercadoria do colonialismo, e seu posterior desenvolvimento capitalista no país, foi o corpo negro escravizado. Este foi um processo que não se fixou apenas na esfera física da opressão, mas estruturou funcionamento e organização social e política do país. Sendo assim, as dinâmicas das relações sociais são totalmente atravessadas por essa hierarquização racial.

Insiste-se: a literatura negra se mostra excelente possibilidade para promover debates e reflexões em contextos escolares, com vistas a formar consciências e resistências, além de angariar solidários a essas questões que afligem toda a sociedade atual. Afinal, concorda-se com Barthes (1992) quando diz que "a literatura é uma forma de trapacear a língua". Ou ainda, com Orlandi (2005) quando diz que "a palavra serve para dizer e para não dizer". Logo, a coprodução de sentidos deve ser bem mediada pelo docente para que alcance resultados profícuos.

Dessa forma, a literatura pode ser veículo de ideologias ou instrumento de apagamento de ideologias; tudo vai depender da forma como se organizam as suas metáforas, plurissignificações e elementos linguísticos. Um leitor menos atento, pode limitar-se a apenas uma das possibilidades de significação. Daí a importância da mediação didática em aulas de literatura (ou situações/momentos de leitura) na escola, mesmo em contexto de ensino médio, quando o aluno está sedimentando sua capacidade de senso crítico. 
Então, uma intervenção didática em sala de aula, a partir da literatura negra, com ênfase na análise do discurso ideológico materializado nos textos, pode ser substancial para o combate ao racismo, além de favorecer a divulgação de conhecimentos sobre a história e cultura afrodescendente ou afro-brasileira como meio de oportunizar adesão de todos a ações e movimentos antirracistas. Afinal, precisa-se ver a força da fala como mola propulsora para construção de pontes (RIBEIRO, 2017). Para essa autora, a construção de pontes deve substituir a construção de muros.

\section{Racismo estrutural, literatura negra e educação cidadã}

O racismo não é inerente ao ser humano, mas aprendido na convivência com pessoas e estruturas políticas, econômicas e sociais, montadas a partir do conceito de raça proposto pelo modelo de Estado burguês e hegemônico, como forma de manter direitos e interesses de alguns grupos. Na ânsia de conseguir unidade, ou seja, um modelo de sujeito universal, a estrutura de poder termina por classificar as multiplicidades religiosa, sexual, cultural, estigmatizando, domesticando, criminalizando, e até, animalizando o outro. Essa banalização ou naturalização de situações discriminatórias resulta no racismo estrutural (ALMEIDA, 2016).

Fazem-se necessárias, então, ações e movimentos antirracistas em toda a sociedade como maneira de fazer contraponto ao que está posto. Numa atitude de combate ao racismo e de valorização, reflexão e disseminação de saberes que se aproximam ou advêm da ancestralidade negra, ou de outras etnias e minorias, foi instituída, no Brasil, a Lei 10.639/03 e ampliada, posteriormente, pela Lei 11.645/08, objetivando, através da educação, garantir a todos o acesso a esses saberes e conhecimentos que tanto servem como fortalecimento da conscientização de raça quanto ação de combate à discriminação e ao preconceito.

São muitas as dificuldades em romper com tantos anos de escravidão, num país fundado com a exploração e o sangue negro e indígena; faltam aos brasileiros, independentemente da cor, raça ou credo, até mesmo o conhecimento de suas raízes, de sua história. Quando há alguma ação na escola no sentido de uma aproximação entre as diversidades, predomina uma visão distorcida e romântica de não conflito social. Ou seja, combatem-se possíveis conflitos, mas não se trabalha para o envolvimento de todos com o envolvimento em ações e atitudes antirracistas (RIBEIRO, 2019).

A educação pode ser vetor de transformação ou de manutenção e reprodução de valores, ideias e crenças que predominam na estrutura social. O contexto de avanços tecnológicos e 
científicos bem como a constatação recente de que se vivem tempos de incertezas, passam a exigir da escola e da sociedade posicionamentos mais firmes em relação ao respeito ao direito do outro de se sentir representado. Nunca a educação para a libertação, proposta por Paulo Freire, se fez tão necessária.

Desse modo, surge o interesse em alargar os conceitos de cidadania e de favorecer a construção de identidade das minorias, respeitando-lhes seus direitos, ao mesmo tempo em que se alargam os horizontes de conhecimento sobre a história e a cultura negra dos demais alunos, com vistas a uma transformação, a partir da absorção de todos do conhecimento de suas origens, raízes. Freire (1983, p. 80) ensina que:

O educador humanista revolucionário não pode esperar (...) seus esforços devem corresponder com os dos alunos para comprometer-se num pensamento crítico e numa procura da mútua humanização. Seus esforços devem caminhar junto com uma profunda confiança nos homens e em seu poder criador.

Como se percebe, os professores devem estabelecer relação de proximidade e confiança com seus alunos, no sentido de libertá-los, desenvolvendo neles o senso crítico e a autonomia de pensamento. O caráter inacabado dos homens e as transformações constantes sofridas pela realidade exigem que a educação seja contínua (FREIRE, Id.).

E o ensino de literatura mostra-se forte aliado do professor, no combate ao racismo e a preconceitos de diversas ordens, principalmente, quando essa literatura é entendida não somente como escrita imaginativa ou aquilo que recebe o aval da crítica antes de ser entregue a sociedade (CULLER, 1999), mas como terreno fértil de onde os sentidos emergem, graças ao seu caráter ficcional, plurissignificativo e subjetivo. A literatura enquanto prática de linguagem que busca acompanhar as transformações, ao avançar, renova-se a si mesma (CULLER, Id.), permitindo a comparação, a contraposição de textos, de personagens, enfim, a contraposição com outros discursos, com o intuito de buscar novos sentidos e significações.

Nessa perspectiva, e compreendendo a escola como lugar de circulação e produção de saber e de construção de identidades; e a literatura como instrumento capaz de provocar a reflexão e a sensibilização do outro, buscou-se fazer uma incursão em contextos de ensino médio para tentar entender o que mudou nas escolas depois da implantação das duas leis, a 10.639/2003 e a 11.645/2008? Como transitam a literatura e a cultura negra em contextos escolares, no ensino médio, depois da vigência dessas leis? 
Enfim, essas e outras questões podem ser respondidas a partir de uma análise das respostas dadas pelos professores e alunos de ensino médio ao questionário online, instrumento de coleta de dados, na pesquisa que antecedeu a escritura deste artigo.

\section{Análise dos dados e discussão}

A linguagem tomada como prática social interativa sugere reflexões sobre sujeito, ideologia, história e a própria linguagem. Orlandi (2005) esclarece que o sujeito do discurso se constrói na linguagem, entendendo-a em sua historicidade. Segundo a autora (Id, p. 96), "É a ideologia que torna possível a relação palavra-coisa. Para isso têm-se as condições de base, que é a língua, e o processo, que é discursivo, onde a ideologia torna possível a relação entre o pensamento, a linguagem e o mundo". Ou seja, o funcionamento da ideologia determina a combinação da língua e da história. Ou ainda, a ideologia é constitutiva do sujeito e dos sentidos.

Assim, as relações engendradas nas estruturas sociais e nas instituições sobrepõem ideias e valores de acordo com interesses e movimentos interiores dentro dessa estrutura. Essas relações de linguagem, mediação necessária entre a realidade social e o mundo natural, ocorrem entre sujeitos e produz sentidos, ou seja, acontece entre interlocutores e resulta em efeitos diversos, sempre possibilitados pela língua (ORLANDI, 2005).

A concepção de que os sistemas simbólicos são instrumentos de dominação para legitimar o poder hegemônico parece encontrar ressonância nas ideias de Foucault (1999) quando trata de questões ligadas à disciplina do corpo e descreve como as políticas de coerções, como a manipulação (anatomia política ou mecânica do poder) possibilitam o domínio sobre o corpo do outro, exigindo-lhe eficácia e docilidade.

Daí a importância de o aluno ter espaço de fala na escola; sentir-se acolhido na e pela escola. Daí também a importância da sociolinguística quando propõe que seja repensada a imposição de normas hegemônicas da língua, sem questionamentos sobre quais ideologias estão por trás dessa decisão. Cabe à escola o combate ao preconceito linguístico e quaisquer outras formas de preconceito. Os alunos precisam ter o direito de se comunicar e levar o debate antirracista para além dos espaços acadêmicos; esse debate precisa sair do nível de militância e atingir a sociedade brasileira por inteiro (RIBEIRO, 2019).

A análise do corpus de pesquisa apontou para que entre os alunos (37) e professores (12) que participaram da pesquisa respondendo ao questionário, 35,29\% se autodeclaram 
brancos; $29,41 \%$ pretos e $35,29 \%$ se autodeclaram pardos. Dentre os professores, $82,35 \%$ trabalham em escolas públicas e $17,65 \%$ na rede particular. Com respeito ao ano de escolaridade, somente $9,09 \%$ são alunos de $1^{\circ}$ ano e $90,91 \%$ são alunos do $3^{\circ}$ ano do ensino médio. Em relação à idade dos participantes, tem-se que 5,88\% têm menos de 15 anos; 58,82\% estão na faixa etária entre 17 e 19 anos e 35,29\% acima dos 20 anos.

Os respondentes são moradores de Senhor do Bonfim-BA ou de municípios da microrregião; ou ainda da capital, Salvador- BA. Dois professores são de outros estados da federação. Quando perguntados sobre a afinidade que mantêm com a leitura, 11,76\% dos alunos afirmam ler apenas o suficiente para se informar; 41,18\% afirmaram gostar de ler; $41,18 \%$ gostar muito de ler e 5,88\% não gostar de ler. Dentre os professores, 92\% afirmaram gostar muito de ler e $8 \%$ apenas para se manterem informados. Em relação ao tipo de leitura de suas preferências, dentre professores e alunos, 35,29\% preferem romances, contos, crônicas, enfim, textos literários; $11,76 \%$ textos de divulgação científica; $11,76 \%$ dão prioridade aos textos informativos, como notícias, reportagens e 41,18\% admitem ler textos de gêneros e discursos diversos

Ao serem interrogados sobre o acesso à literatura produzida por autores negros, $76,47 \%$ afirmaram já ter lido autores da literatura negra e 23,53\% não leram ainda autores negros. Dentre os autores negros mais lidos e citados pelos entrevistados aparecem: Machado de Assis, Kabengele Munanga, Grada Kilomba, Chimamanda Adichie, Carolina Maria de Jesus, Conceição Evaristo, Djamila Ribeiro, Milton Santos, Lázaro Ramos, Angela Davis, Cruz e Souza, Silvio Almeida, dentre muitos outros citados.

É válido observar que nem todos os autores que fizeram literatura de temática negra na literatura brasileira do século passado são aceitos pela crítica como autores de literatura negra, uma vez que a criação das personagens ou das narrativas (ou mesmo a análise, o ponto de vista) foi construída a partir da ótica do branco e não da subjetividade do preto. Monteiro Lobato é um exemplo de autor branco que fez literatura de temática negra, mas porque tanto a narrativa quanto os personagens, os pontos de vista, etc., foram criados a partir da subjetividade branca, não é considerado pela crítica como autor de literatura negra. Já Lima Barreto, por exemplo, é negro e fez literatura negra, segundo a crítica (D’ÂNGELO, 2010).

$\mathrm{Na}$ análise dos dados recolhidos, percebeu-se que nem todos os entrevistados têm consciência de que Machado de Assis era negro. Isso é reflexo ainda do processo de 
"embranquecimento" sofrido pelo autor para ser aceito na imprensa editorial da época. Assim, essa verdade emerge somente há bem pouco tempo.

Com respeito às obras mais lidas, tem-se que Olhos d'Água, Quarto de despejo, O perigo de uma história única, Clara dos Anjos, Na minha pele, O ódio que você semeia, Água negra e outras águas; e os contos: Negrinha e Jardineiro Timóteo, foram as mais citadas. Quando perguntados sobre o suporte em que se encontram os textos que leem, o livro/revista/jornal impresso próprio e o $e$-book $e$ textos da internet foram os mais apontados.

Dentre os professores e alunos de $3^{\circ}$ ano do Ensino Médio, está a maioria dos que admitiram ter utilizado ou ter tido acesso à leitura de autores negros. Alguns dos entrevistados assinalaram que a leitura completa de algumas dessas obras foi motivada pelas leituras e debates realizados em sala de aula, porém aconteceu fora da escola, por interesse e iniciativa própria, tanto de alguns alunos como de alguns professores.

Questionados sobre a possibilidade de já terem presenciado alguma cena, ou mesmo, sido atingidos por alguma ofensa ou tratamento desrespeitoso ou preconceituoso, por causa da cor da pele ou dos traços físicos, foram várias as frases ouvidas e cenas que presenciaram. Dentre elas, "Quem ela pena que é? Neguinha metida!”; "Ei, você aí, Nega do cabelo duro! É com você mesma que estou falando"- expressão de chamamento que partiu de uma professora para sua aluna negra. Ou ainda: "Isso só pode ser coisa de preto! E preto nem gente é!"- uma pessoa branca ouviu essa frase direcionada a uma pessoa negra; "Os pretos são mais racistas"uma pessoa ouviu essa frase sendo dirigida a uma mulher negra.

É interessante evidenciar que todos os que fizeram referência a uma ou mais frases racistas que ouviram, registraram sentimentos de desprezo e revolta por terem ouvido coisas tão desagradáveis. Outros entrevistados demonstraram sentimentos, ora de impotência diante da realidade ora de esperança em dias melhores. Porém, notou-se que algumas falas tentaram neutralizar as diferenças, suavizando a cor da pele ou traços físicos do outro; ou ainda, forçando uma aproximação que não existe com o diferente, como forma de tornar invisível a negritude, como denuncia Ribeiro (2019).

Algumas dessas falas foram "esse meu amigo nem é tão negro, sabe. Tem a pele assim mais clara, os cabelos lisos (...) ele é bonito!”, como se a beleza estivesse atrelada à cor da pele das pessoas. Ou ainda "Convivo com pessoas pretas desde minha infância e não vejo diferenças", uma forma comum na sociedade de tentar "invisibilizar" o racismo, atrapalhando, 


\section{Alêunghbras}

IN' 2596-2671

Revista AlembrA - RA Confresa-MT

Volume 3. Número 6. Janeiro a junho 2021

inclusive, as iniciativas para combatê-lo, o que Ribeiro (2019) denuncia como sendo uma romantização da democracia racial, construída por Freyre (2001), em Casa Grande e Senzala.

Enxergar a negritude é um dos primeiros passos para a conscientização, solidarização e tomada de posição em favor da militância antirracista. Enxergar a negritude implica a aceitação do outro como potencialidade que é (RIBEIRO, op. cit., p. 43). Logo, mesmo tendo a intenção de se mostrar uma pessoa receptiva e solidária, ao proferir palavras assim, o indivíduo deixa transparecer o racismo internalizado que dá sustentação ao racismo estruturante na sociedade brasileira.

Alguns entrevistados narraram resumidamente cenas de preconceito a que assistiram ou mesmo que foram dirigidas a eles, como: $\mathrm{O}$ caso de uma tia, membro de uma família negra, porém de pele mais clara do que a pele do demais familiares que, como forma de 'embranquecer a raça', não estimulava os namoros das sobrinhas com rapazes de cor preta. Mesmo sendo um rapaz bonito e apresentável, essa tia dizia que era feio e apontava a cor da pele como motivo maior para não ver beleza no pretendente da sobrinha. Essa cena se repete cotidianamente em nosso meio e com tanta frequência que já se banalizou.

Outra cena foi a de uma senhora que, por conta da cor da pele de sua funcionária doméstica e, diante do sumiço de um objeto que a patroa guardava em uma gaveta, atribuiu o furto à doméstica e ofendeu-a com palavras bastante fortes, mesmo sem ter provas contra a moça. Essa cena nos faz refletir sobre tantas outras bastante comuns também na sociedade brasileira, mas "invisibilizada" pelo poder e privilégio dos brancos: a do filho do rico que, geralmente dono ou associado ao poder, comete o crime e quem vai preso é o filho do jardineiro, já que não tem posse, não tem voz (direito à fala), nem lugar de fala ${ }^{4}$ e nem privilégios, serve de exemplo. Aliás, não consegue nem mesmo se constituir cidadão.

Em relação à frequência com que a escola trabalha literatura negra, 29,41\% afirmou que frequentemente; $41,18 \%$ poucas vezes; $23,53 \%$ raramente e $5,88 \%$ nunca. Com respeito à avaliação dos entrevistados quanto ao espaço dado à literatura negra na escola que frequentam, seja como aluno ou como professor, os entrevistados assim se manifestaram: 70,59\% defenderam a ideia de que não é suficiente o espaço dado, nem aprovam a abordagem didática que esses textos recebem e $29,41 \%$ defenderam que é suficiente e trabalhada de maneira crítica.

\footnotetext{
${ }^{4}$ A expressão lugar de fala compreendida como oportunidade de as mulheres negras se posicionarem a partir de suas realidades, que são diferentes das realidades das mulheres brancas, e assumirem-se protagonistas de suas reivindicações para que as pautas não sejam uniformizadas, já que os anseios não coincidem (RIBEIRO, 2017).
} 
Alguns entrevistados, professores e alunos, admitiram que, apesar de nem sempre ter tido acesso a livros na escola, foi-lhes dado espaço para manifestações culturais no dia da Consciência da Negra, ou outros momentos oportunos, trazendo pessoas que são referência na literatura e produção de saberes da cultura negra, a exemplo da filósofa Djamila Ribeiro, para proferir palestras. Ou ainda, apresentação de bandas de música e danças em que o ritmo africano predominou; demonstração de rituais religiosos, em forma de performances artísticas, filmes sobre a temática negra.

Houve críticas, por parte de alguns alunos, e referência por parte de um professor, com relação a alguns professores que oportunizam a leitura de textos literários, informativos ou teóricos, científicos sobre racismo e antirracismo, entretanto não intensificam os debates, deixando-os na superficialidade. Ou seja, não conseguem nem mesmo sensibilizar os alunos para uma tomada de consciência sobre a condição de subalternidade que é imposta ao negro na sociedade brasileira por conta do racismo. E na realidade, há que se ir para além da sensibilização e conscientização, pois faltam ações, movimentos, atitudes e engajamento de toda a sociedade.

Foi solicitado aos entrevistados que fizessem referência a alguma passagem, trecho, cena, enfim, ao que mais gostaram ou que os tenha marcado nos textos lidos. Dentre os registros encontram-se alguns mais voltados para o incentivo e direcionamento na escolha da profissão, como "a leitura do livro Quem menos anda voa me fez descobrir que me identificava com a arte de encenar" [fala de um entrevistado do $3^{\circ}$ ano].

Outros trechos ou cenas citados voltam-se mais para a possibilidade de uma riquíssima reflexão sobre o racismo, a exploração do negro pelo homem branco, propondo um novo olhar sobre a resistência negra de Palmares e dos negros no período colonial, a exemplo da fala de outro entrevistado "a leitura de literatura negra me possibilitou ter outro olhar para a história que nos contam sobre Palmares (...) nem sempre o que nos contam corresponde à verdade”. Desse modo, atesta-se o valor de se trabalhar com literatura negra em contextos escolares de ensino médio, como uma ação em prol de mobilização de toda a sociedade em favor das teorias antirracistas.

Foi feita referência também à obra de Hugo Canuto, que não é negro, mas relata parte importante da história dos negros, entremeando a narrativa com a presença de Orixás, a partir de pesquisas a fontes confiáveis, o que contribuiu para que a leitura fosse prazerosa e a cultura e religiosidade afrodescendente recebessem tratamento respeitoso na obra, como "a presença 
de Orixás nas narrativas de Hugo Canuto foi construída a partir de pesquisas sólidas da história, das crenças, cultura e religiosidade afrodescendente, o que dá credibilidade e promove um olhar diferenciado às religiosidades de origem africana" [fala de outro entrevistado].

Resumindo, as aulas de leitura de textos de literatura e cultura negra devem invadir os contextos escolares e serem abordadas pelos diversos professores de maneira a colaborar para reflexões sobre a construção da identidade negra dos alunos (e de alguns professores) que se autodeclaram pretos; para dispersarem informações sobre a história e a cultura afrodescendente; e, de certa forma, para a conscientização dos problemas sociais advindos do racismo, pois se espera muito mais que apenas conscientização e solidarização às questões racistas. São urgentes atitudes e movimentos de militância antirracistas bastante consistentes.

\section{Considerações finais}

A leitura é um recurso didático utilizado por quase todos os professores e em quase todas as disciplinas. Os textos sobre literatura negra e sobre cultura afrodescendente, em prosa ou verso, podem/devem ser utilizados em contexto escolares no ensino médio, como meio de disseminar a história e a cultura africanas, além de fortalecer a representatividade negra. São muitos os personagens e as narrativas que despertam admiração do leitor, servindo-lhe de catarse ou de absorção de suas subjetividades para abrandar problemas existenciais ou de outras ordens. Afinal, a literatura se presta a isso: fruição, catarse, aquisição de conhecimento ou informação, etc.

Assim, compreende-se como natural que a escola, em contexto de ensino médio, também dê sua contribuição, estimulando o autoconhecimento e a construção de práticas antirracistas, como sugere Djamila Ribeiro (2019), em seu livro Pequeno Manual Antirracista, tendo como mote a leitura e a reflexão sobre cultura e literatura negra.

Concluindo, toma-se a liberdade de sugerir o poema Vozes-mulheres, de Conceição Evaristo, como mais um exemplo para mostrar que questões sobre a história e a ancestralidade negra podem ser trabalhadas em sala de aula, a partir da trajetória das mulheres, de suas subjetividades negras ainda guardadas na memória coletiva; ou de como foram sendo construídas verdadeiramente ao longo da história. Senão vejamos.

\section{Vozes-mulheres - Conceição Evaristo}

A voz de minha bisavó/ ecoou criança/ nos porões do navio.

Ecoou lamentos de uma infância perdida./A voz de minha avó ecoou obediência./ Aos brancos-donos de tudo./A voz de minha mãe 


\section{Alêsingora}

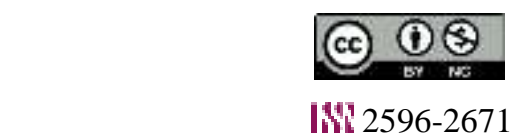

Revista AlembrA - RA Confresa-MT

Volume 3. Número 6. Janeiro a junho 2021

ecoou baixinho revolta/ no fundo das cozinhas alheias/ debaixo das trouxas roupagens sujas dos brancos/ pelo caminho empoeirado/ rumo à favela.

A minha voz ainda ecoa versos perplexos/ com rimas de sangue/ e fome.

A voz de minha filha/ recolhe todas as nossas vozes/ recolhe em si as vozes mudas caladas/ engasgadas na garganta./ A voz de minha filha recolhe em si/ a fala e o ato./ O ontem- o hoje- o agora./ Na voz de minha filha se fará ouvir a ressonância/ o eco da vida-liberdade.

Fonte: Poemas da recordação e outros movimentos.

Um texto como esse pode ser o mote inicial para uma aula de literatura, história, filosofia, sociologia, enfim, de qualquer outro componente curricular. A criatividade e o compromisso do professor com a conquista de uma realidade mais humana, mais ética e mais justa é que vão decidir a mediação e as reflexões que deverão suceder à leitura desse poema.

\section{Referências}

ALMEID, Sílvio. Racismo estrutural. São Paulo: Editora Pólen Livros, 2016.

ANDREWS, Georg Reid. O negro no Brasil e nos Estados Unidos. São Paulo: Lua Nova: Revista de Cultura e Política, vol. 2, n. 1, junho, 1985.

BARTHES, Roland. Aula. 3ed. São Paulo: Cultrix, 1992.

BERND, Zilá. Introdução à literatura negra. São Paulo: Brasiliense, 1988.

BERND, Zilá. (Org.). Antologia de Poesia Afro-brasileira: 150 anos de consciência negra no Brasil. Belo Horizonte: Mazza Edições, 2011, p. 149.

BORGES, Juliana. Encarceramento em Massa. In: RIBEIRO, Djamila. (ORG.). Feminismos Plurais. São Paulo: Editora Pólen Livros, 2019.

BRASIL. Lei 10.639 de 9 de janeiro de 2003. D.O.U., de 10 de janeiro de 2003.

BRASIL. MEC. Proposta de Plano Nacional de Implementação das Diretrizes Curriculares Nacionais da Educação das Relações Étnico-raciais e para o Ensino de História e Cultura Afro-Brasileira e Africana - Lei 10.639/2003. Brasília, 2008.

CULLER, Jonathan. Teoria literária: uma introdução. Trad. Sandra Vasconcelos. São Paulo: Beca Produções Culturais, 1999.

CUTI, Luís Silva. Literatura negro-brasileira. São Paulo: Selo Negro, 2010.

D’ÂNGELO, Helô. Lima Barreto e o racismo de nosso tempo. Revista Cult, maio de 2017. Disponível em: https://revistacult.uol.com.br/home/lima-barreto-e-o-racismo-do-nosso-tempo. Acesso em 26/11/2010 
DIJK, Teun A. van. Discurso antirracista no Brasil. In: Palestra proferida no Projeto Abralin ao vivo: Linguistcs online. Disponível em:

https://www.youtube.com/watch?v=4yQyRSnfxZ8. Acesso em: 09/11/2020.

EVARISTO, Conceição. Poemas da recordação e outros movimentos. Belo Horizonte: Nandyala, 2008.

JESUS, Carolina Maria de. Quarto de Despejo: diária de uma favelada. Edição Popular, 1960.

FREIRE, Paulo. Pedagogia do oprimido. 12a edição. Rio de Janeiro: Paz e Terra, 1983.

FREYRE, Gilberto. Casa-grande \& senzala. 42ed. Rio de Janeiro: Record, 2001.

FOUCAULT, Michel. A verdade e as formas jurídicas. Trad. Roberto Cabral de Melo Machado e Eduardo Jardim Morais. Rio de Janeiro: Nau Ed., 1999.

MALDONADO-TORRES, Nelson. Sobre la colonialidad del ser: contribuciones al desarrollo de un concepto. In: CASTRO-GÓMEZ, Santiago.; GROSFOGUEL, Ramón. (Orgs.) EI giro decolonial. Reflexiones para una diversidad epistémica más allá del capitalismo global. Bogotá: Universidad Javeriana-Instituto Pensar, Universidad Central-IESCO, Siglo del Hombre Editores, 2007. p. 127-167. Disponível em: http://ramwan.net/restrepo/decolonial/17-maldonado-colonialidad\%20del\%20ser.pdf

NOGUEIRA, Maria Alice \& NOGUEIRA, Cláudio M. Martins. Bourdieu e a educação. 3ed. Belo Horizonte: Autêntica, 2009.

ORLANDI, Eni. Análise de discurso: princípios e procedimentos. 6. ed. Campinas, SP: Pontes, 2005.

RIBEIRO, Djamila. Pequeno manual antirracista. São Paulo: Companhia das Letras, 2019.

RIBEIRO, Djamila. Lugar de fala. In: Feminismos plurais. Edição revista em parceria com a Editora Pólen Livros, 2017.

SANTOS, Boaventura Sousa e Meneses, Maria Paula (Orgs.) Epistemologias do Sul. São Paulo: Cortez, 2010. 